\title{
Pengembangan Keahlian Penggunaan Microsoft Excel bagi Instruktur Pelatihan TIK Nasional bagi Disabilitas
}

\author{
Tri Sugihartono ${ }^{1}$, Rahmat Sulaiman ${ }^{2}$, Sarwindah ${ }^{3}$ \\ ${ }^{1,2}$ Program Studi Teknik Informatika FTI ISB Atma Luhur, Pangkalpinang \\ ${ }^{3}$ Program Studi Bisnis Digital FEB ISB Atma Luhur, Pangkalpinang \\ E-mail: 'trisugihartono@atmaluhur.ac.id, ${ }^{2}$ rahmatsulaiman@atmaluhur.ac.id, \\ 3indah_syifa@atmaluhur.ac.id
}

\begin{abstract}
Abstrak
Bakti Kominfo mempunyai tugas di bagian TIK yaitu membangun infrastruktur Jaringan IT di daerah tertinggal. Selain itu juga BAKTI Kominfo mempunyai andil untuk mengembangkan sumber daya manusia yang mempunyai keahlian dibidang IT dan mengikuti perkembangan zaman saat ini yaitu dunia Digital. Oleh karena itu BAKTI Kominfo melakukan pelatihan kepada guru guru TIK untuk memberikan wawasan sebagai bekal membimbing siswa Disabilitas untuk mengikuti Pelatihan dan Kompetisi TIK Nasional. Salah satu materi pelatihannya yaitu Excel. Dalam kegiatan ini bekerja sama dengan ISB Atma Luhur untuk melatih guru guru TIK dengan materi Microsoft Excel. Pelatihan ini berlangsung selama 3 hari secara berturut turut menggunakan Zoom Meeting. Dalam kondisi Pandemi Covid-19 ini tidak mematahkan semangat untuk selalu ber inovasi membuat dan mengadakan pelatihan pelatihan untuk mengembangkan kemampuan dari pada Sumber daya guru guru TIK untuk mendampingi siswa Disabilitas. Yang tujunannya untuk menjaring kompetensi dan bakat dari siswa siswi Disabel yang terpendam. Dengan adanya kegiatan pelatihan ini kemampuan guru TIK semakin luas dalam penggunaan Microsoft Excel 2016. Dan dari peserta pelatihan menyarankan untuk selalu berinovasi dalam membuat pelatihan pelatihan serupa dengan materi yang lain lagi serta untuk bias didampingi selalu pada saat pelatihan bahkan pasca pelatihan.
\end{abstract}

Kata kunci: Ms.Excel, Zoom Meeting, Bakti Kominfo, Disabilitas, Covid-19

\begin{abstract}
Bakti Kominfo has tasks in the ICT section, namely building IT network infrastructure in disadvantaged areas. In addition, BAKTI Kominfo also has a role in developing human resources who have expertise in the IT field and keep up with the current developments, namely the Digital world. Therefore, BAKTI Kominfo conducts training for ICT teachers to provide insight as a provision to guide students with disabilities to take part in National ICT Training and Competitions. One of the training materials is Excel. In this activity in collaboration with ISB Atma Luhur to train ICT teachers with Microsoft Excel material. This training lasts for 3 consecutive days using Zoom Meeting. In the conditions of the Covid-19 Pandemic, this did not discourage us from always innovating in making and holding training courses to develop skills from ICT teacher teacher resources to assist students with disabilities. The goal is to capture the hidden competences and talents of students with disabilities. With this training activity, the ability of ICT teachers to use Microsoft Excel 2016. And from the training participants suggested to always innovate in making training training similar to other materials and to always be accompanied during training and even after training.
\end{abstract}

Keywords: Ms. Excel, Zoom Meeting, Kominfo Service, Disability, Covid-19 


\section{PENDAHULUAN}

Perkembangan Teknologi Internet dan Sistem informasi tumbuh semakin pesat dan canggih di seluruh belahan dunia [1][2][3][4][5] semakin banyak daerah yang sebelumnya sulit untuk di akses kini bias dengan mudah di jangkau[3], kemudahan akses[4] dan pertumbuhan system informasi ini sendiri sudah selayaknyadigunakan secara merata oleh seluruh perangkat pemerintahan dan pelayanan industry, dari tingkat kabupaten hingga desa.

Salah satu teknologi Digital [5] adalah Teknology Video Conferene, saat ini berbagai instansi yang melakukan kegiatan dari rumah menggunakan video conference. Salah satu media yang digunakan dalam video Conference adalah Zoom Meeting. pada saat ini, salah satunya adalah aplikasi Zoom Meeting. Akibat dampak Covid-19[1] ini zoom meeting sering digunakan oleh perusahaan untuk tetap memonitor karyawan saat melakukan Work From Home (WFH).

Pandemi Covid -19[2] telah mendesak perubahan ola hidup manusaia untuk lebih banyak beraktivitas di ruang digital. Pemerintah melalui program transformasi digital berupaua menginklusikan seluruh lapisan masyarakatdalam pembangunan termasuk disabilitas. Dalam rangka meningkatkan literasi teknologi informasi dan komunikasi (TIK), Badan Aksesibitas Telekomunikasi dan Informasi (BAKTI) Kementerian Komunikasi dan Informatika akan menyelenggarakan Pelatihan dan Kompetisi TIK Nasional secara Daring bagi Disabilitas di 34 Provinsi di Indonesia.

Kegiatan ini mencakup empat bidang TIK yaitu E-Commerce, Desain 2D, Excel, Google Sheet ddan Google Form. Pelatihan dan kompetisi ini menjangkau e 34 provinsi di seluruh Indonesia. Kategori khusus akan diberikan kepada peserta dari daerah - daerah tertinggal, terdepan dan Terluar (3T). Pelatihan dan Kompetisi TIK Nasional secara Daring bagi Disabilitas akan diselenggarakan selama lima (5) hari pada tingkat provinsi dengan pembagian durasi, tiga hari pelatihan dan 2 hari kompetisi. Kegiatan ini mencakup NTT, NTB, Sulawesi, Maluku, dan Papua yang di selenggarakan pada 13 - 15 November 2020.

Kegiatan Pkm ini, Bakti Kominfo mengadakan Training of Trainer bagi guru TIK SLB yang akan mentransfer ilmu kepada siswa siswi disable yang akan mengikuti Pelatihan dan Kompetisi TIK Nasional secara daring. Pada kegiatan PkM ini, ISB Atma Luhur selaku Instruktur dalam kegiatan ini yang mengisi materi Ms. Excel. Pelatihan kegiatan PkM ini berlangsung secara Daring menggunakan Zoom Meeting.

\section{METODE}

Kegiatan Program Pengabdian Kepada Masyarakat (PkM) ISB Atma Luhur ini dilaksanakan secara daring, menggunakan aplikasi Zoom Meeting pada tanggal 13 - 15 November 2020 dan diikuti oleh 20 peserta yang berasal dari ututsan untusan provinsi NTT, NTB, Sulawesi, Maluku, dan Papua. Sasaran dari Program PkM ini adalah Tenaga Pendidik TIK/Non TIK dari Sekolah Luar Biasa (SLB). Pelatihan dilaksanakn melalui beberapa tahapan, diantaranya (pada tabel 1).

Tabel 1 Jadwal Pelaksanaan Kegiatan Pengabdian Masyarakat

\begin{tabular}{|c|c|c|}
\hline TANGGAL & KEGIATAN & VIA \\
\hline 11-12 November 2020 & Briefing & ZOOM Meeting \\
\hline 13-15 November 2020 & Training of Trainer & ZOOM Meeting \\
\hline 16-17 November 2020 & Pengumpulan Berkas & Whatsapp \\
\hline 14 Desember 2020 & Pembuatan Sertifikat & $\begin{array}{c}\text { BAKTI } \\
\text { KOMINFO }\end{array}$ \\
\hline 9-13 Februari 2021 & Pembuatan Laporan & ISB Atma Luhur \\
\hline
\end{tabular}

Kegiatan PkM ini berupa pendalaman materi Ms. Excel, dan juga pembahasan dari kisi kisi yang akan diperlombakan dalam kompetisi TIK Nasional. Adapun materi yang disampaikan dalam kegiatan PkM ini adalah sebagai berikut (pada Tabel 2). 
Tabel 2 Silabus

\begin{tabular}{|c|c|c|}
\hline HARI & WORKSHOP & MATERI \\
\hline \multirow{14}{*}{$\begin{array}{l}\text { Jumat s.d Minggu13- } \\
15 \text { November } \\
\qquad 2020\end{array}$} & \multirow{14}{*}{$\begin{array}{l}\text { Training of Trainer } \\
\text { Guru SLB tentang } \\
\text { Aplikasi } \\
\text { Pengolahan Angka }\end{array}$} & - Pengenalan Fungsi FiturpadaExcel \\
\hline & & - Pembuatan Dokumen \\
\hline & & - Setting Basic Worksheet \\
\hline & & - Insert Picture \\
\hline & & - Insert and Manage Tabel \\
\hline & & - $\quad$ Insert Grafik and Manage Chart \\
\hline & & - Pengatur Fungsi Formula \\
\hline & & - Mencetak Dokumen \\
\hline & & - Pengolahan Penyimpanan File \\
\hline & & $\begin{array}{l}\text { - Pengolahan Keamanan Data / } \\
\text { File }\end{array}$ \\
\hline & & - HLOOK UP dan VLOOKUP \\
\hline & & - Keamanan Informasi \\
\hline & & $\begin{array}{l}\text { Keamanan, Kesehatan dan } \\
\text { Keselamatan Praktik } \\
\text { Pemanfaatan TIK }\end{array}$ \\
\hline & & - Tugas Harian \\
\hline
\end{tabular}

Mitra kegiatan Pengabdian ini adalah Bakti Kominfo. Pelatihan ini bertujuan agar dapat membantu guru guru TIK / Non TK SLB dapat mengimplementasikan dan mengaplikasikan dalam sekolah dan khususnya dapat membimbing dan mendidik siswa siswi dalam memahami Materi Materi dalam penggunaan excel. Adapun manfaat dari kegiatan Pengabdian ini adalah Ilmu dan wawasan peserta menjadi luas dan bertambah dalam penggunaan dan memfungsikan Excel dalam kehidupan sehari hari yang dapat membantu dan mempermudah dalam pakerjaan .

Sebagai tim pelaksana kegiatan PkM ini adalah para Dosen Teknik Informatika dan Bisnis Digital ISB Atma Luhur. Dosen ISB Atma Luhur memiliki SDM yang berkompeten untuk melaksanakan kegiatan ini. Dalam kegiatan PkM ini dibimbing dan dipandu oleh dosen yang sesuai dengan tugasnya dan keahlian guna memberikan solusi yang tepat guna dan implementatif.

Tabel 3 Tim Pelaksana PkM Pelatihan Excel

\begin{tabular}{|c|l|l|l|}
\hline No & Nama Dosen & Program Studi & Tugas \\
\hline 1 & Tri Sugihartono, M.Kom & Teknik Informatika & Pemateri Excel \\
\hline 2. & Rahmat Sulaiman, M.Kom & Teknik Informatika & Pemateri Keamanan Informasi \\
\hline $3 `$ & Sarwindah, MM & Bisnis Digital & $\begin{array}{l}\text { Pemateri Keamanan Kesehatan dan } \\
\text { Keselamatan Praktik Pemanfaatan TIK }\end{array}$ \\
\hline
\end{tabular}

Selama palaksanaan kegiatan kami bagi waktu dan pelaksanaannya berdasarkan materi dan tugas masing masing, adapun pembagian waktu pelaksanaannya dapat dilihat pada Diagram dibawah ini. 


\section{Range Pembagian Waktu Pelaksanaan}

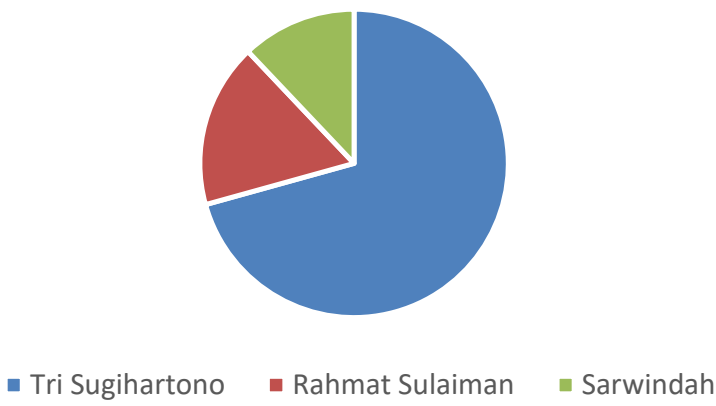

Gambar 1 Range Pembagian Waktu Pelaksanaan

Selain tim Pelaksanan kegiatan yang terdiri dari Dosen ISB, juga ada panitia yang membantu teknis dalam mempunyai tugas dalam teknis kelancaran kegiatan PkM ini, yang teridiri dari 2 mahasiswa.

Tabel 4 Panitia Tim Teknis Kelancaran PkM Pelatihan Excel

\begin{tabular}{|c|l|l|}
\hline No & Nama Mahasiswa & Program Studi \\
\hline 1 & Heri Anggara & Teknik Informatika \\
\hline 2 & Marcellino & Teknik Informatika \\
\hline
\end{tabular}

\section{HASIL DAN PEMBAHASAN}

Pelaksanaan Pelatihan Pengembangan Kemampuasn dan Keahlian Penggunaan Microsoft Excel 2016 dilaksanakan dalam 1 sesi dengan jumlah peserta adalah 20 orang secara Virtual menggunakan ZOOM Meeting. Kegiatan ini dapat diselenggarakan dalam 3 hari kerja. Setiap peserta akan diberi modul pelatihan dan diberi kesempatan untuk praktek langsung menggunakan komputer/ Laptop masing-masing. Adapun langkah-langkah pelaksanaan pelatihan adalah sebagai berikut :

\section{PELAKSANAAN PELATIHAN/WORKSHOP}

Kegiatan Pengabdian Kepada Masyarakat telah berlangsung dengan lancar. Jadwal pelaksanaan pelatihan ini berlangsung sebagai berikut :

Tanggal Pelatihan : 13 November - 15 November 2020

Sifat pelatihan : Zoom Meeting- Online

Waktu Pelatihan : : 08.0016 .00

Hari Pelatihan : Jumat - Minggu

\section{PESERTA PELATIHAN/WORKSHOP}

Peserta pada Training of Trainer 'Pelatihan dan Kompetisi TIK Nasional Secara DaringBagi Disabilitas berjumlah 20 Guru SLB. Berikut ini daftar tabel peserta ToT: 
Abdimasku, Vol. 4, No. 2, Mei 2021: 67-72

Tabel 5 Daftar Tabel Peserta

\begin{tabular}{|c|l|c|l|}
\hline No & Nama Peserta & No & Nama Peserta \\
\hline 1 & Nelvin & 11 & Moni Waku \\
\hline 2 & Laode A Kasim & 12 & Ismawati Muhammad \\
\hline 3 & Haidir Yasman Kardi & 13 & Ikdar Kokodaka \\
\hline 4 & Asura Let-Let & 14 & Markus Mangamba \\
\hline 5 & Muhammad Harrys Usman & 15 & Laode \\
\hline 6 & Kasriadi Azis & 16 & Hasriani \\
\hline 7 & Fredik Mauritz Taek & 17 & Alfaris Johanes Topurtawi \\
\hline 8 & Andi Ernawati & 18 & Adrianus Jauhari \\
\hline 9 & Fatma Rosita & 19 & Adhan Jhayangkara \\
\hline 10 & Erma Astuti Mukadas & 20 & Berti Malingara \\
\hline
\end{tabular}

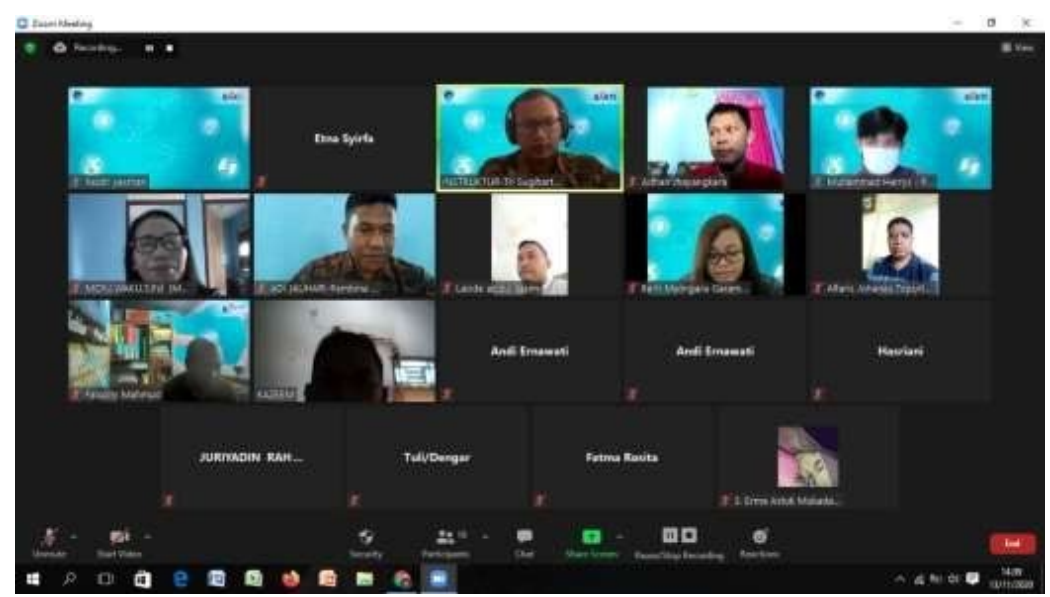

Gambar 2 Daftar Peserta Training of Trainer Pelatihan dan Kompetisi TIK Nasional Secara Daring Bagi Disabilitas

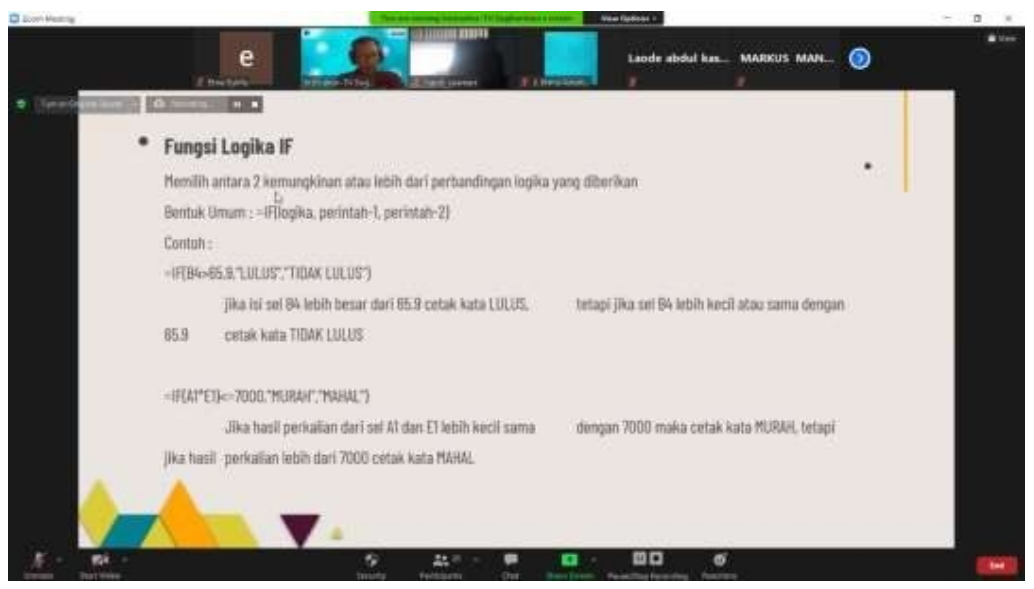

Gambar 3 Share Screen Materi ToT oleh Instruktur

Di akhir kegiatan, para peserta diminta untuk menmapiakan kesan dan pesan terkait dengan pelatihan untuk meningkatkan keahlian dalam penggunaan Excel ini. Hasil dari pesan dan kesan dari peserta adalah sebesar 70-90 \% menilai bahwa pelatihan ini bermanfaat dan minta untuk diadakan pelatihan selanjutnya dengan materi yang berbeda dan bersifat dengan 
pendampingan terhadap peserta peserta.

\section{KESIMPULAN DAN SARAN}

Dalam kondisi saat ini, dunia sedang di landa dengan pandemic covid-19, terutama di negara Indonesia, yang merupakan salah satu negara yang terdampak. Walaupun dalam kondisi saat ini, aktivitas ataupun program program suatu instansi tidak jalan ditempat. Program PkM ISB Atma Luhur bekerja sama dengan BAKTI Kominfo, mengadakan pelatihan bagi Guru TIK untuk wilayah Timur Indonesia secara daring (ZOOM MEETING), dalam kegiatan ini bertujuan untuk mempersiapkan instruktur instruktur bagi peserta kompetensi TIK Nasional. Kegiatan ini dinilai bermanfaat oleh para peserta dan berharap untuk didakan kembali dengan materi yang berbeda melalui dengan kegiatan kegiatan yang bersifat pendampingan.

\section{UCAPAN TERIMA KASIH}

Para Penulis mengucapkan terima kasih kepada Bakti Kominfo yang telah mendukung program ini berupa dana yang telah dikeluarjan untuk kelancaran dan kesuksesan PkM Pelatihan untuk Meningkatkan Kemampuan dalam Penggunaan Micorosoft Excel dalam mempersiapkan Instruktur untuk Persiapan Kompetisi TIK Nasional bagi Disabilitas ini dapat berjalan dengan baik dan lancar.

\section{DAFTAR PUSTAKA}

[1] C. Rahmad, A. D. W. Sumari, A. P. Kirana, M. Z. Abdullah, and S. E. Sukmana, "Perangkat Desa Melek Digital dan Kreatif: Pelatihan Pengembangan Konten Digital Desa Ngijo Kabupaten Malang," Abdimasku J. Pengabdi. Masy., vol. 4, no. 1, p. 7, 2021, doi: 10.33633/ja.v4i1.140.

[2] D. Aqmala, "Pemanfaatan E-Commerce Sebagai Media Startup Bisnis Pada Anak-Anak Panti Asuhan Riyadlul Jannah Dan Panti Asuhan Al Mustaghfirin Semarang," Abdimasku J. Pengabdi. Masy., vol. 4, no. 1, p. 55, 2021, doi: 10.33633/ja.v4i1.146.

[3] I. Gamayanto, S. Novianto, and H. Haryanto, "Pelatihan \& Implementasi Social Media Profiling Untuk Meningkatkan Kompetensi Pada SMA Negeri 3 Semarang," Abdimasku J. Pengabdi. Masy., vol. 4, no. 1, p. 26, 2021, doi: 10.33633/ja.v4i1.148.

[4] E. Helmud, and T. Sugihartono, "Pelatihan Pembuatan Aplikasi Menggunakan Visual Studio Community 2017 dan Android Studio dengan Database SQL Server 2014," Abdimas J. Pengabdi Masy., vol. 1, No. 1, p. 9, 2019.

[5] T. Sugihartono, A. A. Alkodri, Supardi, and Sarwindah, "Pengembangan Skill Kemandirian Siswa Prakerin Tahun 2020 Menjadi Wirausahawan Muda di Bidang Teknisi dan Desainer," Abdimas J. Pengabdi Masy., vol. 1, No. 2, p. 1, 2020. 